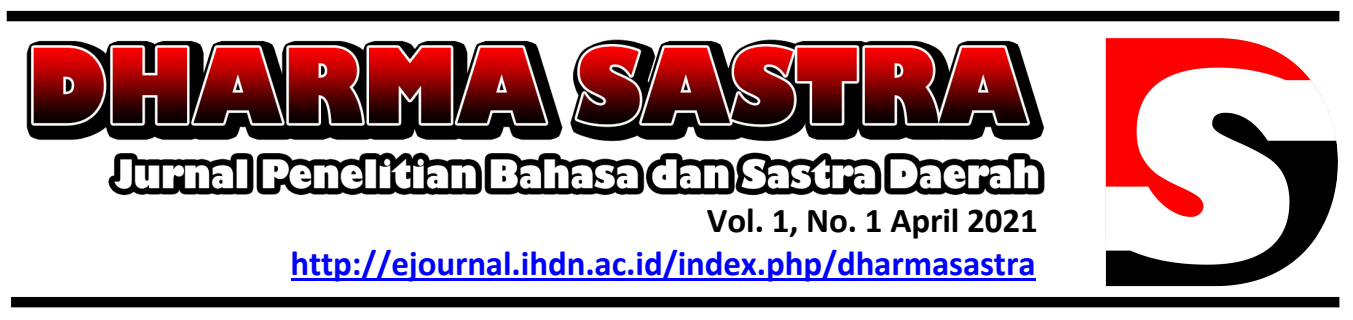

\title{
Analisis Nilai dalam Kakawin Aji Palayon
}

\author{
A.A. Made Pujiari
}

UHN IGB Sugriwa Denpasar , Email : agungratih86@gmail.com

\begin{tabular}{l}
\hline \multicolumn{1}{c}{ Info Artikel } \\
\hline Diterima : 27 Maret 2021 \\
Direvisi : 31 Maret 2021 \\
Diterbitkan : 2 April 2021 \\
Keywords: \\
Kakawin, Aji Palayon \\
\end{tabular}

\begin{abstract}
Kakawin is one of the literatures used in Yadnya ceremonies in Bali in particular. In the yadnya ceremony, the activity of developing kakawin accompanies the ceremony in a melodious and meaningful way. Kakawin is also commonly referred to by other terms, namely wirama, tembang gede and sekar agung. One of the kakawin who plays an important role in increasing the belief and trust of the Balinese people in the existence of the afterlife is Kakawin Aji Palayon. Kakawin Aji Palayon tells of the journey of the atma (spirit) from dying (coming out of the body) to Sang Hyang Widhi in Heaven. Kakawin or literary work has values related to all things that are good. Likewise in Kakawin Aji Palayon, it contains good values of life that encourage people to be positive in their own lives or in society.
\end{abstract}

\section{Pendahuluan}

Kehidupan masyarakat Bali tidak dapat dipisahkan dari kegiatan upacara yadnya. Dalam pelaksanaan kegiatan upacara yadnya kesusastraan menjadi bagian yang cukup penting. Kesusastraan menggunakan bahasa sebagai salah satu medianya. Dengan bahasa kegembiraan, harapan, kesedihan, perasaan, dll dapat diungkapkan. Kakawin merupakan salah satu kesusastraan yang digunakan dalam kegiatan upacara yadnya di Bali pada khususnya. Kakawin dan parwa merupakan karya sastra Jawa Kuna yang hidup subur pada zaman Majapahit. Ketika Majapahit jatuh dan masuknya agama Islam, maka karya sastra kakawin banyak yang diselamatkan di Bali yang masih satu kepercayaan dengan Majapahit yaitu Hindu (Zoetmulder, 1983). Kakawin biasa juga disebut dengan istilah lain, yaitu wirama, tembang gede dan sekar agung. Dari bentuk ini kemudian lahir beberapa istilah untuk sastra kakawin, seperti puisi Jawa Kuno, puisi naratif Jawa Kuno, prosa lirik Jawa kuno, prosa berirama Jawa Kuno (Jirnaya, 2017: 295).

Dalam upacara yadnya kegiatan menembangkan kakawin mengiringi pelaksanaan upacara dengan merdu dan bermakna. Aktivitas menembangkan kakawin atau sering disebut makakawin dapat dilihat salah satunya dalam upacara pitra yadnya, mulai dari meninggal, ngeringkes, berangkat ke kuburan, penguburan/pembakaran jenasah, ngereka, nganyut, ngerorasin sampai ngelinggihang. Salah satu kakawin yang sangat berperan penting dalam meningkatkan keyakinan dan kepercayaan masyarakat Bali terhadap eksistensi dunia akhirat adalah Kakawin Aji Palayon. Kakawin Aji Palayon menceritakan perjalanan sang atma 
(roh) dari meninggal (keluar dari tubuh jasmani) sampai kepada Sang Hyang Widhi di Surga (Astuti.dkk, 1998:66).

Kakawin Aji Palayon sesuai dengan namanya, yaitu "aji" berarti "ilmu" dan "palayon" (pa + layon, layon adalah jenazah) yang berarti "kejenazahan atau kerohan" merupakan dharmagita yang diperuntukkan pada upacara Pitra Yadnya atau yadnya yang dipersembahkan kepada roh suci leluhur (Gautama, 2009: 369). Hal tersebut membuat penulis tertarik untuk meneliti nilai-nilai kehidupan yang terkandung dalam Kakawin Aji Palayon.

\section{Metode}

Penelitian kualitatif adalah jenis penelitian yang digunakan dalam penelitian ini, dengan pendekatan studi pustaka. Adapun jenis data yang digunakan adalah jenis data kualitatif dengan sumber data yang diperoleh darin buku maupun sumber penunjang lainnya. Data diperoleh dengan metode pustaka, dimana metode analisis data menggunakan deskriptif kualitatif dengan runtutan reduksi data, penyajian data, kesimpulan data. Penyajian data menggunakan tata cara penyajian informal.

\section{Pembahasan}

Kakawin Aji Palayon merupakan karangan Almarhum Ida Bagus Putu Bek. Beliau merupakan seorang sastrawan yang ahli dalam berbagai bidang kesenian. Kakawin ini menggunakan bahasa Jawa Kuna yang ditulis diatas kertas folio dengan panjang $32 \mathrm{~cm}$ dan lebar $21 \mathrm{~cm}$ serta jumlah halaman 21 lembar. Kakawin Aji Palayon diikat oleh guru lagu seperti kakawin pada umumnya. Ada lima guru lagu yang terdapat pada Kakawin Aji Palayon yaitu Sronca, Sardhula Wikridita, Malini, Sardula dan Wasantatilaka. Guru lagu Sronca digunakan secara berulang sebanyak dua kali. Guru lagu ini sangat mengikat jalan cerita naskah karena merupakan satu kesatuan yang tidak dapat dipisahkan satu dengan lainnya (Astuti.dkk, 1998:65-66).

Dalam kajian tentang nilai-nilai yang terkandung dalam Kakawin Aji Palayon, kita akan mencoba menelaah nilai-nilai apa yang tersirat dan tersurat dalam Kakawin Aji Palayon. Karya sastra mempunyai nilai-nilai yang berhubungan dengan segala sesuatu hal yang baik. Begitu pula dalam Kakawin Aji Palayon, di dalamnya terkandung nilai-nilai baik kehidupan yang mendorong orang untuk berbuat positif di dalam kehidupannya sendiri atau bermasyarakat.

\section{Nilai Etika}

Etika dalam Kamus Besar Bahasa Indonesia berarti ilmu tentang apa yang baik dan apa yang buruk dan tentang hak dan kewajiban moral (akhlak). Nilai etika adalah nilai yang berkaitan dengan benar dan salah yang dianut oleh golongan atau masyarakat. Kehidupan manusia tidak dapat dipisahkan dari persoalan nilai dimana manusia hidup bermasyarakat akan selalu terlibat dalam persoalan nilai.

Kakawin Aji Palayon merupakan salah satu karya sastra klasik yang mengandung nilai etika. Dharma baik yang dilakukan oleh sang atma semasa hidupnya diceritakan dalam kakawin ini. Sang atma semasa hidupnya digambarkan berbudi luhur dengan perbuatan baiknya. Ketika telah meninggalkan badan kasarnya menuju akhirat sang atma mendapatkan pahala kebaikannya tersebut. Keluhuran budi sang atma dapat dilihat dari beberapa bait dibawah ini. 
Pupuh 62 Sardhula Wikridita:

62. Ah ah ah kitangatma lungguha kitaywa wring ri sang bragala,

Bhoh bhoh e kitangatma tan hana sudosanteki limpad aji,

Na sabdanya Bhatari Durga mangalem sang atma kawlasarep,

Wetning sira ring manah nira waratma agya ngungsir stana.

Terjemahannya:

Wahai kamu sang atma duduklah kamu jangan merasa takut kepada sang bregala. Diamlah kamu sang atma sungguh tidak ada dosamu yang terdapat dalam pengetahuanku. Demikianlah katanya Bhatari Durga menyanjung sang atma yang penuh pengharapan, oleh karena tujuan hatinya sang atma akan mencari tempat.

Pupuh 135-138 Wirama Malini.

135. Sahananikang hyang mangsa nongsongkingatma.

Wra mudita mojar dhuh kitatman ajawri.

Madana kita hanang kon hyang manongsong kita tah,

Apayapana kitang satye sukirtin ta dharmma.

Terjemahannya:

Semua dewa menyongsong sang atrna mendekat. Dengan kata kasih sayang beliau (dewa) berkata, wahai kamu atma jangan takut, oleh karena para dewa menyuruhnya untuk menyongsongmu, oleh karena juga kamu setia dan berbudi luhur.

136. Gyata lumaku mareng lokatma sudhati sucya.

Mangalapi phala diwya mwang sakalwir suratya.

Apana kita sudharmma hyang Widhisharda masih.

Grhita kanaka asri yeka bhuktinta ri ngka.

Terjemahannya:

Dengan segera pergi ke tempat para atma yang sangat suci, Meningkatkan hasil yang baik dengan segalanya yang baik, Oleh karena kamu berbudi luhur maka Tuhan akan mengasihimu. Rumah emas yang serba mulia itu kamu nikmati disana.

137. Manadhukara tikang atma manis rum wuwusnya.

Atibya luwu linghing hyang mamujya ringatma.

Hulunatiki tanawruh sastra matranya nora.

Aji karepasanatmekanta tar wruh hulunta.

Terjemahannya:

Dengan sangat girangnya sang atma berkata lembut dan sopan. Amat merdunya para dewa berkata memuji sang atma, hamba ini (atma) tidak tahu dengan ilmu, hanya sedikit yang aku ketahui, Yang namanya Aji kelepasan (ilmu melepaskan jiwa) juga aku tidak mengetahuinya.

138. Api kita tatan-awruh ring kuranta luhangta.

Twi yana kita susila neng jagat gung twi bhakti.

Ri bhuwana pati dhira byakta sang hyang isasih. 
Terjemahannya:

Meskipun kamu tidak mengetahui keutamaan jalan (maksud) tersebut, sungguh jika kamu telah berbuat baik di dunia dengan memiliki hati yang penuh hormat. Di alam semesta kalau memiliki budi pekerti yang luhur jelaslah Hyang Widhi akan memberkahimu. Demikianlah sabda beliau (dewa) maka sang atma menjadi senang.

Dalam bait bait tersebut digambarkan bahwa sang atma dengan budi luhur yang baik akan mendapatkan tempat yang baik pula di alam nirwana. Perbuatan yang kita lakukan pada saat masih hidup merupakan tabungan akhirat kita saat menuju ke alam nirwana. Jika banyak hal baik yang kita lakukan maka keluhuran budi baik tersebut akan melekat pada sang atma. Begitu pula sebaliknya jika banyak hal buruk yang kita perbuat maka perjalanan sang atma nantinya akan terhalangi atau mendapat rintangan menuju alam nirwana, maka pergunakan setiap kesempatan untuk berbuat baik dan benar dalam kehidupan sehingga Hyang Widhi akan memberkati seperti gambaran dalam bait bait kakawin diatas.

\section{Nilai Keindahan}

Keindahan adalah sifat-sifat (keadaan dan sebagainya) yang indah. Kasusastraan yang merupakan bagian dari bahasa dan kesenian pastinya mengandung nilai keindahan. Dengan demikian unsur kesenian (termasuk di dalamnya kesusastraan) misalnya mempunyai fungsi guna memuaskan hasrat naluri rnanusia akan keindahan (Koentjaraningrat, 1979:229).

Keindahan kakawin Aji Palayon dapat dilihat pada pelukisan tentang keadaan-keadaan alam sepanjang jalan yang dilalui sang atma dalam perjalanannya menuju ke surga. Pelukisan keadaan alam sekitar, pemandangan alam yang indah dapat dilihat pada beberapa bait di bawah ini.

Pupuh 71- 75 Sronca:

71. Manuk mahuranya muni,

Aninggali panidranya.

Hana mareng kayu nedeng mawah,

Waneh hana ya ngungsir puspa.

Terjemahannya:

Burung-burung berkicauan, Meninggalkan tempat tidurnya.

Ada yang bertengger pada pohon yang sedang berbuah.

Ada juga yang lain menuju pohon bunga

72 Hana mareng kati mageryang muni,

Halah menjuhnya ngiswan rasmy,

Denwal dening sikatikang pudak,

Na dakya Iwir swaraning ganta,

Terjemahannya:

Ada yang sedang terbang dengan riang bersuara.

Bersenang-senang saling menyentuh yang kelihatan indah. 
Ditembus dengan harumnya batang pudak.

Demikian keadaannya bagaikan suaranya bajra pendeta.

73 . Witing ketaki sadrasa,

Rwanya lolya tinampuh samirana,

Hastaning maha wiku pama,

Kala sira ngasirwada,

Terjemahannya:

Pohon keteki yang menggiurkan.

Daunnya gemulai ditiup angin.

Diumpamakan sebagai tangan sang pendeta.

tatkala beliau melakukan pemujaan.

74. Kusuma ruru hatur skarura,

Rebu kamelek himper dhumaning dipa,

Lata wilet heneng ketaki,

Ganitri kunda lopama.

Terjemahannya:

Rontoknya kembang bagaikan persembahan/taburan hunga.

Terendam bagaikan padamnya api pada lampu.

Pohon lata (bun lata) membelit pohon keteki.

bagaikan ganitri dalam api pemujaan.

75. Swaraning sadpada ring kesara,

Lwa panjayajayaning wiku,

Ngarcana hyang Goripati

Marapwan sangatma manggih asuka.

Terjemahannya:

Suaranya kumbang pada sari kembang.

Keadaannya itu bagaikan bunyi matra sang pendeta.

Menuju Sang Hyang giripati.

Agar sang atma mendapat kesenangan.

Pelukisan keindahan alam tergambarkan ketika sang atma melakukan perjalanan menuju surga. Keindahan alam baik tumbuh tumbuhan, suara kumbang, suara burung, serta keindahan suasana alam lainnya dilukiskan dalam bait bait kakawin. Keindahan surga juga dapat dirasakan dalam gambaran perlajanan sang atma. Surga sebagai tempat tujuan akhir sang atma digambarkan sebagai tempat yang indah dan menawan. Untuk melukiskan tentang keindahan surga penulis kakawin ini mempergunakan hal-hal yang indah di dunia yaitu permata dan intan. Rumah Sang Hyang Widhi (Tuhan) digambarkan sebagai sebuah rumah yang dihiasi oleh permata serta temboknya terbuat dari intan yang berkilauan. Penggambaran keindahan tersebut dapat digunakan sebagai angan angan kita sebagai manusia agar selalu berbuat kebaikan dan kebenaran dalam menjalani kehidupan, sehingga saat tiba waktunya 
sang atma dapat menikmati keindahan yang menakjubkan dalam perjalanannya menuju akhirat. Seperti tertulis dalam Pupuh 141-142 Wirama Malini.

141.Akasagami para hyang Iwir kagadara daran.

Hana salu sasi kantaneng yawaning suloka.

Rikana ta wara atman dinyusan de wara hyang,

Jinaya jaya ri rsya hyang kabeh mursiteya.

Terjemahannya:

Diangkasa yang tinggi para dewa bagaikan burung yang terbang berputar-putar. Ada tempat yang bulat yang terlihat dari luar surga. Disana atma itu dimandikan oleh dewata. Dipuja, dimantrai oleh para resi, dan dewapun memujanya.

142.Ri wusira wara atma nganjali jong watek hyang.

Athamaha sira mangke ri dwaraning grdewa, Inaterakenira hyang swarnna diwya grharum, Jwalita mirahi tambak Iwir ninaksatra kumnar.

Terjemahannya:

Setelah atma itu selesai menyembah kehadapan Tuhan (Hyang Widhi). Kemudian sang atma itu sekarang berada di gapura dewa, Diantarkannya ke rumah dewa yang rumahnya indah dihiasi permata. Sangat bercahaya intannya pada tembok bagaikan disinari cahaya bintang.

\section{Nilai Perjuangan, Kewaspadaan}

Kakawin Aji Palayon juga mengandung nilai-nilai perjuangan, kewaspadaan. Perjuangan sang atma dalam mencapai surga sungguh merupakan perjuangan yang berat dan panjang serta melelahkan. Diceritakan bahwa banyak hambatan yang menghadang perjalanan sang atma untuk menuju ke surga. Bermacam-macam harnbatan diternui oleh sang atma dalam perjalanannya, misalnya akan dimangsa buaya, dihadang oleh raksasa wanita, dihadang oleh anjing yang besar serta macan hitam yang menakutkan, mau dimakan oleh seorang butakala dan yang terakhir akan dimangsa oleh empat butakala yang lebih mengerikan dibandingkan dengan butakala yang seorang.

Semua halangan dan rintangan tersebut dapat dilalui oleh sang atma dengan perjuangan yang dilandasi oleh keluhuran budi. Disamping keluhuran budi, keberhasilan sang atma melewati rintangan serta hambatan adalah sikapnya yang waspada terhadap sesuatu hal. Kewaspadaan sang atma dapat dilihat pada bait dibawah ini :

Pupuh 77, 78, 98 Sronca:

77. Tatkala sangatma tekeng nadi,

Rikana ta sirasoca.

Hinawuhaya saka ring banu,

Tutuknya mangang atibhisana

Terjemahannya:

Tatkala sang atma sampai di sungai.

Disana dia berkumur dan mencuci muka. 
Ada seekor buaya berada dalam air.

Yang mulutnya melebar menakutkan.

78. Sang wuhaya wawang maso,

Harep-anadah sang waratma,

Tambis sangatma sinahut,

Yan tan saksana lumumpat.

Terjemahannya:

Sang buaya itu segera maju.

Hendak menyergap sang atma

Hampir-hampir sang atma diterkam.

Kalau tidak cepat melompat.

98. Nahan ling sangatmatiyatna

Hana cambra ireng katon mangso,

Angungaluhur Iwira dryanak,

Sinongan jaladara kandel.

Terjemahannya:

Demikianlah kata sang atma dengan waspada.

Ada seekor anjing besar dilihatnya menghampirinya.

Sangat besar dan tinggi yang seperti beranak.

Berada dekat air kemudian bergumul,

Dari beberapa contoh bait diatas terlihat bahwa sang atma memiliki kewaspadaaan yang tinggi sehingga beberapa kali terhindar dari bahaya. Waspada berarti selalu siap dalam menghadapi segala sesuatu. Dari uraian atau contoh diatas kita dapat mengambil hikmah yaitu bahwa di dunia ini banyak terdapat ketidakpastian dan marabahaya sehingga setiap manusia yang mau berhasil dalam kehidupannya harus memiliki sikap yang waspada.

\section{Kesimpulan}

Kakawin Aji Palayon merupakan satu di antara karya sastra dari sastrawan Bali. Ida Bagus Putu Bek. yang ditulis dalam Bahasa Jawa. Kakawin ini menceritakan tentang perjalanan sang atma ketika meninggalkan jasad dari dunia menuju kepada Sang Hyang Widhi di surga. Perjalanan sang atma ini mendapat banyak hambatan dari Bhatara Durga dan bhutabhutinya, buaya, raksasa perempuan, macan, anjing yang besar, dan Butakala. Namun pada dasarnya hambatan-hambatan tersebut dapat dikalahkan sehingga ia berhasil mencapai surga. Hambatan-hambatan tersebut sebenarnya bertujuan untuk mengalahkan emosi, ketakutan, dan membersihkan serta menyucikan sang atma.

Kakawin Aji Palayon mengandung nilai etika, nilai keindahan, nilai perjuangan, kewaspadaan. Generasi selanjutnya sebaiknya mewarisi nilai nilai tersebut. Nilai nilai yang terkandung dalam kakawin Aji Palayon hendaknya dapat disebarluaskan kepada masyarakat, sehingga dapat dijadikan pedoman, acuan, atau pelajaran dalam menjalani kehidupan di dunia. Dengan penggambaran dalam kakawin ini kita sebagai manusia yang pastinya suatu 
saat akan meninggal dan sang atma sudah siap menghadapi karma yang dilakukan semasa hidup sebagai bekal tabungan menuju alam nirwana.

\section{Daftar Pustaka}

Renggo Astuti, Elizabeth T. Gurning, I Made Purna, I Wayan Rupa .1998. Kajian Nilai Budaya Naskah Kuno Kakawin Aji Palayon. Jakarta: Departemen Pendidikan dan Kebudayaan. Gautama, Nyoman Budha. 2009. Kamus Bahasa Bali (Bali-Indonesia). Surabaya: Paramita

Jirnaya, I Ketut. 2006. "Metode dan Teknik Praktis Mengajar Mawirama di Sekolah." Makalah dalam Seminar Nyastra Diselenggarakan oleh PWII Korwil Bali.

Koentjaraningrat. 1972. Beherapa pokok Antropologi Sosial. Jakarta: PT. Dian Rakyat. 1992. Kebudayaan. Mentalitas, dan Pembangunan. Jakarta: PT Gramedia.

Zoetmulder, P.J. 1983. Kalangwan, Sastra Jawa Kuna Selayang Pandang. Diterjemahkan oleh Dick Hartoko. Jakarta: Djambatan. 